\title{
Einsteinium declassified
}

\author{
Discovered during secret testing by the United States, Joanne Redfern tells us about element 99 and why \\ its namesake cautioned against the very technology that led to its creation.
}

O $\mathrm{n}$ the first of November 1952, in a top secret test known as Mike, the United States detonated the 'Sausage' - the world's first hydrogen bomb. The explosion annihilated the entire Pacific island of Elugelab, but it wasn't all devastation; at the same time it created two new elements that their discoverers would later name einsteinium and fermium. The explosion was colossal, being more powerful than all of the high explosives used in World Wars I and II combined ${ }^{1}$. In an instant, an enormous number of neutrons (around $10^{24}-10^{25} \mathrm{~cm}^{-2}$, ref. 2) blasted into the uranium atoms used in the bomb. Some of these atoms captured 15 neutrons each - resulting in very heavy uranium isotopes - before rapidly undergoing seven beta decays. The result was a new element with an atomic number of 99 and an atomic mass of 253.

Radioactive debris - including element 99 - mushroomed out of the explosion in a 60-mile-wide cloud. Keen to understand more about the science of thermonuclear explosions, the US Government sent fighter jets flying through the cloud to sample the radioactive fall-out by using special filter papers attached to their wing tanks ${ }^{2}$. The detailed analysis fell to Albert Ghiorso and colleagues at the University of California, Berkeley according to Ghiorso, the results were entirely unexpected ${ }^{3}$.

The team detected a unique radiation signal that they deduced must have come from the hitherto unknown element 99 . They later detected the same signal (and that of element 100) from radioactive coral debris gathered from neighbouring islands. The miniscule amount of element 99 (fewer than 200 atoms in total $^{4}$ ) made the discovery all the more remarkable. Frustratingly, the team were not allowed to say a word as the details of the Mike test remained classified.

To get around this, Ghiorso's team set about making element 99 by other means.

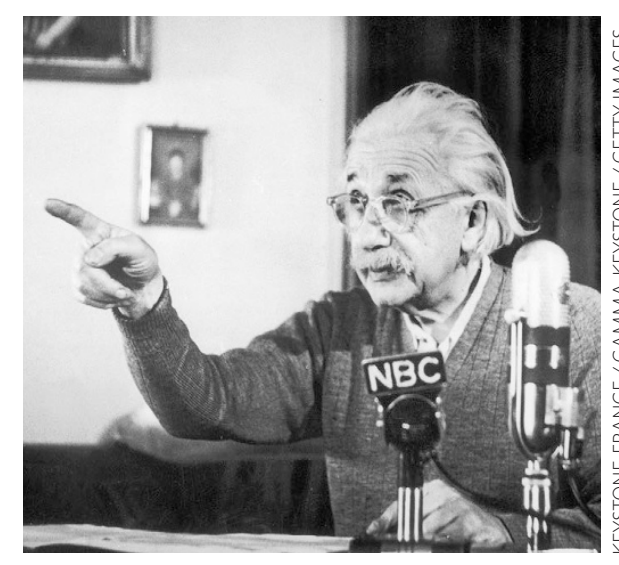

Einstein warns of the dangers of developing the hydrogen bomb (12th February 1950).

They discovered that bombarding ${ }^{238} \mathrm{U}$ with nitrogen ions produced a short-lived isotope of element 99, and they published their findings in 1954 with a note to acknowledge that prior work on the element existed ${ }^{5}$. A few months later the Mike test was declassified, allowing Ghiorso to report his team's earlier discovery in $1955^{6}$. He also had the honour of choosing the name, einsteinium (Es).

Today scientists produce einsteinium by bombarding plutonium with neutrons in a nuclear reactor, then allowing the resulting isotopes to undergo beta decay. This is a slow process. Indeed, it took until 1961 (nine years after its initial discovery) before scientists managed to make enough einsteinium to observe its form as a silvery metal ${ }^{4}$.

As well as being scarce, einsteinium is difficult to study because it self-destructs. It has nearly 20 different isotopes, all of which are radioactive. The most stable, ${ }^{252} \mathrm{Es}$, has a half-life of about 472 days, but it is difficult to produce and is only available in tiny amounts. ${ }^{253}$ Es is the most common isotope, but it has a half-life of only 20 days. It releases gamma rays and $\mathrm{X}$-rays when it decays, damaging its crystal lattice and hampering any X-ray crystallographic analysis. The intense release of energy (1000 W per gram) also causes einsteinium to glow ${ }^{7}$. Furthermore, because it decays rapidly into berkelium and californium, samples of einsteinium are nearly always contaminated.

Einsteinium is mainly used to make heavier elements, such as mendelevium first discovered by Ghiorso's team when bombarding ${ }^{253}$ Es with alpha particles. In addition, scientists have used its radiation to study accelerated aging and radiation damage, and have examined its potential for medical treatments, although not commercially ${ }^{7}$. Outside of basic research, einsteinium has no practical use. So although its name lends it a familiarity, most of us will never come across even a single atom of einsteinium in our lifetimes.

Einsteinium kicked off a trend for naming new elements after famous scientists, and it is hard to imagine a scientist who would not appreciate this honour. But for Einstein, this particular element seems like an ironic choice; he was a pacifist, vehemently opposed to the development of the hydrogen bomb. $\mathrm{He}$ even recorded a statement for US television show Today with Mrs. Roosevelt (pictured) in which he warned that the hydrogen bomb could annihilate life on earth. So how did he feel about a bomb-born element being named after him? We will never know. He died just a few months before Ghiorso announced einsteinium to the world.

JOANNE REDFERN is a science and medical writer based in Cambridge, UK. e-mail: joannelredfern@gmail.com

\section{References}

1. Nuclear Weapon Archive (accessed 14 August 2016); http://go.nature.com/2fAKydM

2. Hoffman, D. C., Ghiorso, A. \& Seaborg, G. T. The Transuranium People: The Inside Story Ch. 6 (Imperial College Press, 2000).

3. Ghiorso, A. Einsteinium and Fermium (Chemical and Engineering News, American Chemical Society, 2003); http://go.nature.com/2fdCSdz

4. Emsley, J. Nature's Building Blocks: An A-Z Guide to the Elements (Oxford Univ. Press, 2011).

5. Ghiorso, A., Rossi G. B., Harvey, B. G. \& Thompson, S. G. Phys. Rev. 93, 257 (1954).

6. Ghiorso, A. et al. Phys. Rev. 99, 1048 (1955).

7. Haire, R. G. in The Chemistry of the Actinide and Transactinide Elements 3rd edn (eds Morss, L. R., Edelstein, N. M. \& Fuger, J.) 1577-1620 (Springer, 2006).

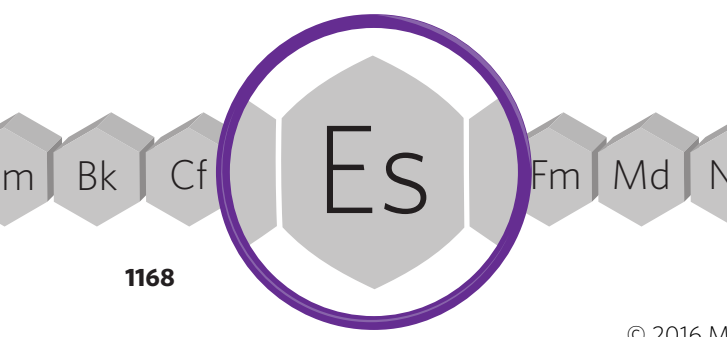

